Portland State University

PDXScholar

$5-1973$

\title{
An experimental study and analysis of Saudi-Arabian \\ - American proxemic behavior as observed in homogeneous and heterogeneous dyadic interactions
}

Gary D. Robinson

Portland State University

Follow this and additional works at: https://pdxscholar.library.pdx.edu/open_access_etds

Part of the Speech and Rhetorical Studies Commons

Let us know how access to this document benefits you.

\section{Recommended Citation}

Robinson, Gary D., "An experimental study and analysis of Saudi-Arabian - American proxemic behavior as observed in homogeneous and heterogeneous dyadic interactions" (1973). Dissertations and Theses.

Paper 2174.

https://doi.org/10.15760/etd.2171

This Thesis is brought to you for free and open access. It has been accepted for inclusion in Dissertations and Theses by an authorized administrator of PDXScholar. For more information, please contact pdxscholar@pdx.edu. 
AN ABSTRACT OF THE THESIS OF Gary D. Robinson for the Master of Arts in Speech presented May 16, 1973.

Title: An Experimental Study and Analysis of Saudi-Arabian-. American Proxemic Behavior as Observed in Homogeneous and Heterogeneous Dyadic Interactions.

APPROVED BY MEMBERS OF THE THESIS COMMITTEE:

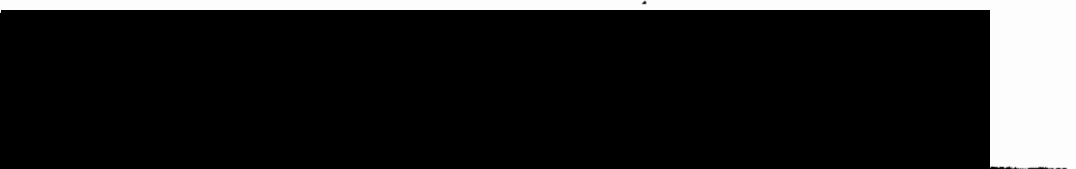

Theodore G. Grove, Chairman

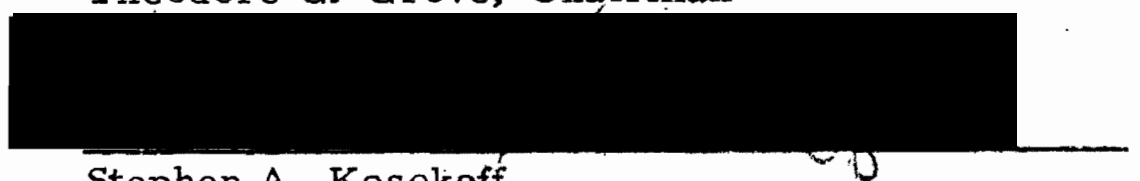

Stephen A. Kosokoff

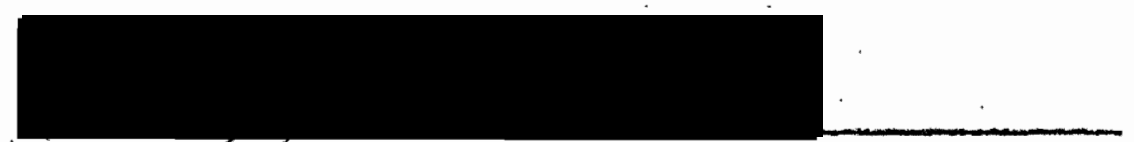

Daniel J. Scheans

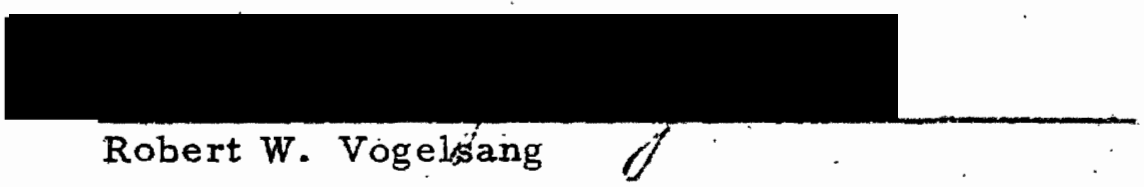

This thesis is an attempt to refine the analysis of an empirical study in intercultural proxemic behavior research conducted by Watson and Graves and is, as well, a partial and modified replication of that study. The hypothesis of this study is that Arabs will exhibit significant differences in proxemic behavior from Americans, with Arabs being closer and more direct in their proxemic behavior than 
Americans. To test this hypothesis, eighteen Saudi-Arabian and eighteen American male students were observed as two groups of nine homogeneous dyads and as one group of eighteen heterogeneous dyads. Seven-minute dyadic interactions in a controlled, laboratory setting were filmed and recorded on video tape. Five proxemic variables were analyzed: sociofugal-sociopetal axis, kinesthetic factors, touch code, visual code, and voice loudness scale. The video taped data were analyzed and scored. Individual scores were averaged to arrive at dyadic scores. Twenty-five t-tests. were calculated to test for possible statistically significant differences between the cultural groups and between both groups of homogeneous dyads and the heterogeneous dyads. No significant differences were found. Thirty Pearson correlations were computed for any possible significant positive correlation among the five variables in Saudi-Arabian - American dyads and in both Saudi-Arabian and American dyads seperately. Three significant positive correlations as well as three significant negative correlations were discovered. The hypothesis of the study was not supported and the findings of the Watson and Graves' study did not appear in the present examination. 
AN EXPERIMENTAL STUDY AND ANALYSIS OF SAUDI-ARABIAN

-AMERICAN PROXEMIC BEHAVIOR AS OBSERVED IN

HOMOGENEOUS AND HETEROGENEOUS

DYADIC INTERACTIONS

by

GARY D. ROBINSON

A thesis submitted in partial fulfillment of the requirements for the degree of.

\section{MASTER OF ARTS \\ in \\ SPEECH}

Portland State University

1973 
TO THE OFFICE OF GRADUATE STUDIES AND RESEARCH

The members of the Committee approve the thesis of

Gar.y D. Robinson presented May 16, 1973.

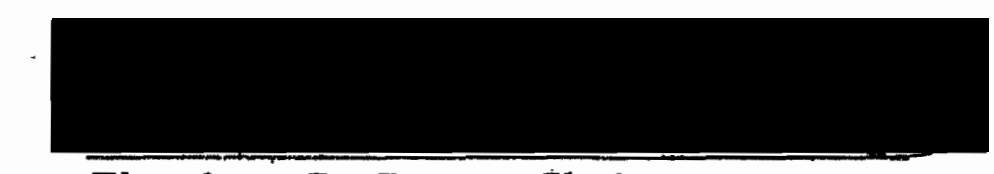

Theodore G. Grove, Chairman

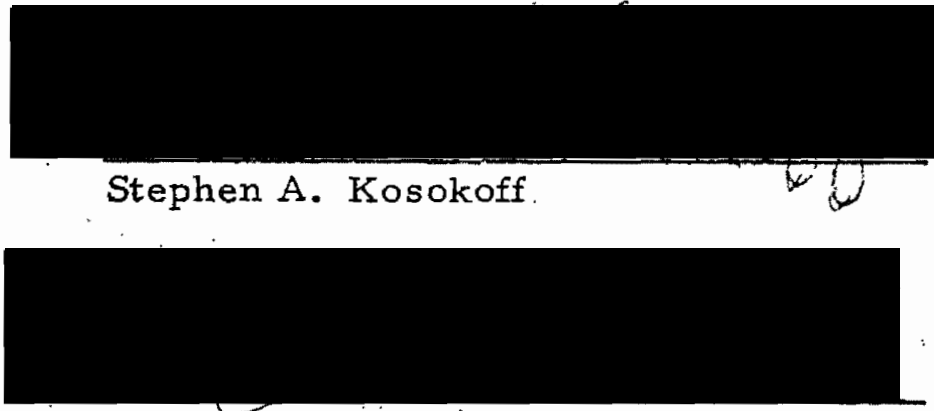

DanieIJ. Scheans

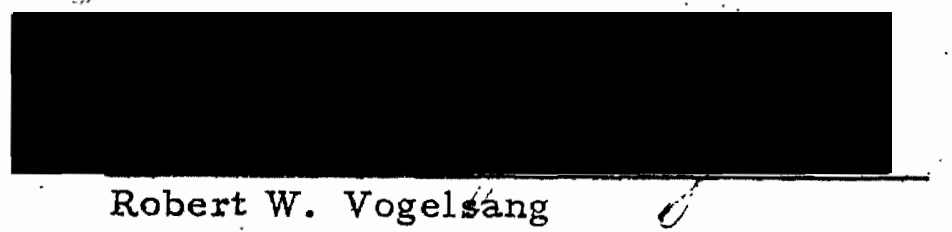

APPROVED:

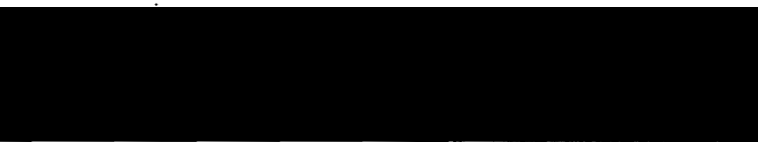

Robert W. Vogelsang, Head, Department of Speech.

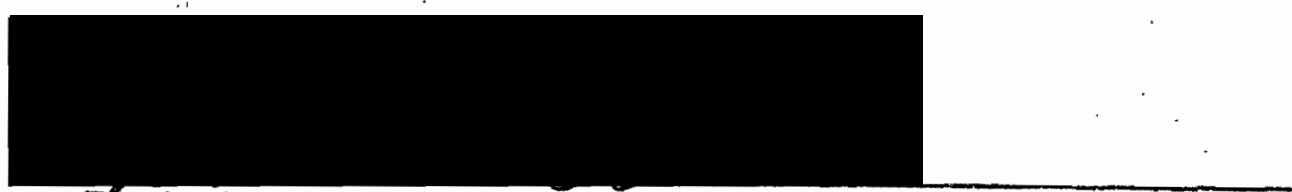

David T. Clark, Dean of Graduate Studies and Research

May 16, 1973 


\section{ACKNOW LEDGEMENTS}

Particular thanks are due to Theodore G. Grove, Chairman of the Thesis Committee, for his invaluable suggestions and directions and for his hours of patient and tolerant review of materials and drafts submitted. The other members of the committee:

Stephen A. Kosokoff, Daniel J. Scheans, and Robert W. Vogelsang, ( are also to be thanked for their helpful suggestions.

Lyle W. Mettler, Director of Television Services at Portland State University, and his staff contributed to this "study in a most significant and constructive way. He and his staff gave freely of their time, equipment, facilities, technical advice, and assistance. Their cooperation made this study possible. 
I $:$ INTRODUCTION $\ldots \ldots \ldots \ldots \ldots \ldots \ldots \ldots \ldots$

II $\quad$ METHODS ....................... 9

Subjects ................... 9

Instructions $\ldots \ldots \ldots \ldots \ldots \ldots \ldots$

Observations .............. 11

Scoring ................... 13

III $\quad$ RESULTS $\ldots \ldots \ldots \ldots \ldots \ldots \ldots \ldots \ldots \ldots$

IV $\quad$ DISCUSSION $\ldots \ldots \ldots \ldots \ldots \ldots \ldots \ldots \ldots$

Suggestions $\ldots \ldots \ldots \ldots \ldots \ldots . \ldots 29$

BIBLIOGRAPHY ........................ 32 


\section{LIST OF TABLES}

TABLE

PAGE

I American and Arab Group Means and Standard

Deviations on Five Measures of Proxemic

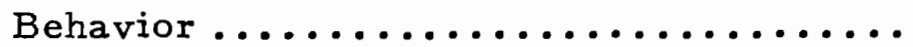

II Arab - American Differences in Proxemic

Behavior Variable 1 -. Axis......... 16

III :Arab - American Differences in Proxemic

: Behavior Variable 2 -- Kinesthetics.... 16

IV Arab - American Differences in Proxemic

Behavior Variable 3 -. Touching...... 17

V Arab - American Differences in Proxemic

Behavior Variable 4 -.. Visual Directness. 17

VI Arab - American Differences in Proxemic

Behavior Variable 5 -... Voice Loudness.. 18

VII Arab - American Differences in Proxemic

Behavior Variable 1 -. Axis ......... 19

VIII Arab - American Differences in Proxemic

Behavior Variable $2 \ldots$ Kinesthetics..... 19

IX Arab - American Differences in Proxemic

Behavior Variable 3 -. Touching...... 20

X Arab - American Differences in Proxemic

Behavior Variable 4--- Visual Directness. 20 
XI Arab - American Differences in Proxemic

Behavior Variable 5---Voice Loudness . 21

XII Pearson Correlations Among Five Measures

of Proxemic Behavior.

XIII : Pearson Correlations Among Five Measures

of Proxemic Behavior for 9 American

Dyads......................

XIV Pearson Correlations Among Five Measures

of Proxemic Behavior for 9 Saudi-Arabian

Dyads 
CHAPTER I

\section{INT RODUCTION}

Edward T. Hall coined the term "proxemics" and defined it as, "the study of how man unconsciously structures microspace", 1 and noted that "people from different cultures interacting with each other could not be counted on to attach identical meanings to the same or similar measured distances between them. What was close to an American might be distant to an Arab. "2 Hall's observations were, however, impressionistic. O. Michael Watson and Theodore D. Graves sought to obtain empirical and 'quantifiable support for Hall's general and subjective findings by observing and scoring proxemic behavior between Arabian and American students. ${ }^{3}$ "At the time [Watson and Graves' study was] undertaken there did not exist, to [Watson's] knowledge, any empirical data concerning the observation and measurement of proxemic behavior using Hall's system of notation". 4

Proxemic behavior has since been given much more attention. Cook; ${ }^{5}$ Forston and Larson; ${ }^{6}$ Goldberg, Kiesler and Collins; ${ }^{7}$ Hall; ${ }^{8}$ Sommer; 9 and Watson ${ }^{10}$ have been among those scholars more recently contributing to the literature. Nevertheless, "... viewing proxemic behavior in the syntactic dimension serves to emphasize 
how little we know about the subject." 1 I "Data pertaining to the relatedness of the proxemics and the linguistics of individual cultures remain to be gathered and this kind of research seems to offer vast possibilities.... ${ }^{12}$

While the Watson and Graves' project served to advance the cause of empirical research in the field, the research was admittedly exploratory in nature and a number of questions and concerns about the study exist, some of which were raised by the authors themselves. ${ }^{13}$ The size of their subject sample was very small (16 Arabs and 16 Americans) and the placement of the subjects at a table appeared to limit the subject's opportunity for freedom and natural interaction as well as to block some distance dimensions from view. The scoring was conducted by the paper-and-pencil method which, while interrator reliability was high; is not thorough and does not allow repetitive measures to be taken. Some important information such as subjects' age and the length of stay in the United States by Arabian students was not reported. One could also question the basic assumption that loudness of voice indicates closeness. While none of these concerns alone may be critical, taken together a replication seems to be warranted.

The present study is concerned with the primary hypothesis formulated by Watson and Graves: that Arabs will exhibit more directness in proxemic behavior than Americans. 14 Their other 
hypotheses concerned regional differences among various Arabian and American groups and are outside the concern of the present study. This study and that of Watson and Graves employed five of Hall's eight categories of proxemic behavior: (a) sociofugal-sociopetal axis, (b) kinesthetic factors, (c) touch code, (d) visual code, and (e) voice loudness scale.

The sociofugal-sociopetal axis dimension scores the relation of the axis of one person's shoulders to that of the other. The Arabs were expected to be more direct than Americans. The kinesthetic factors category relates to the closeness of one person to another. Arabs were expected to interact more closely than Americans. The touch code category provides for the amount of contact during each interaction. Arabs were expected to touch more than Americans. The visual code category measures the directness of eye contact. Arabs were expected to display greater and more direct visual contact. The voice loudness scale rates the loudness of the voice with Arabs expected to talk louder than Americans. Watson and Graves calculated one-tailed $t$-tests and found:

..... all five of the facets of proxemic behavior defined by Hall for which objective measurement could be achieved yielded highly significant differences between. Arabs and Americans in the directions predicted on the basis of Hall's observations. 15

Finally, they figured Pearson correlations among the five measures of proxemic behavior and uniformiy high over-all correlations were 
found. Within the American and Arab groups separately, however, several of the correlations disappeared or even reversed themselves. 16

This study is an attempt to refine the analysis of the Watson and Graves' research project and is, as well, a partial and modified replication of that study. Care has been exercised as much as possible to improve ard increase the rigor of the methodology, to strive for increased reliability and validity, and to take heed of the suggestions for improvement offered by Watson and Graves. Regional differences among the Arab and American populations were not investigated. Rather, Arab sample was entirely Saudi-Arabian and the sample size was increased from four to eighteen with the hope of obtaining slightly higher validity. Likewise, the American population sample was increased to eighteen and, although the American students selected were typically from the Pacific Northwest, all were of NorthEuropean ethnic background representing Hall's "non-contact" group. Hall has identified two basic American types: a "contact" group predominately of southern European origin and a "non-Contact" group. predominately of northern European origin to whom touching strangers and casual acquaintances is circumscribed with numerous proscriptions. 17

The objectives of this study are the same as of the project conducted by Watson and Graves: (1) to record empirical data quantifying 
Arab and American proxemic behavior; (2) to test pragmatically Hall's system for the notation of proxemic behavior to try to uncover any weaknesses or ambiguities inherent in the system; and (3) to test the validity of Hall's impressionistic observations on Arab and American differences. To these objectives, of course, is added the intent to test rigorously Watson and Graves!' findings. The hypothesis of this study is that Arabs will exhibit significant differences in proxemic behavior from Americans, with Arabians being closer and more direct in their proxemic behavior than Americans.

The subject of this study was undertaken because of a feeling of the importance of intercultural non-verbal communication behavior. Proxemic behavior among cultures is more than of passing academic interest to such disciplines as anthropology, political science, psychology, sociology, and speech communication. "In the international business context there are numerous examples of how familiarity with the differences in the adumbrative significance of the setting helped negotiations, while ignorance hindered them."18 On a globe that is not shrinking but has shrunk, mutual understanding among cultures is of increasing value and importance. The study of proxemic behavior may advance such understanding. Hall points out that "when two people of different cultures interact, each uses different criteria to

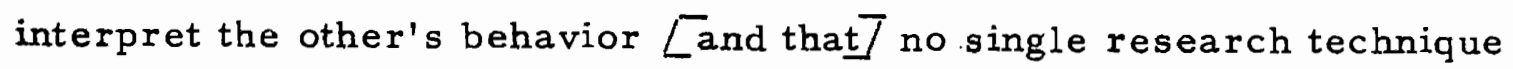
is sufficient in scope to investigate this complex, multi-dimensional 
subject."19 Existing research techniques must be vigorously tested in order to establish confidence in those techniques which may, in turn, bring about better understanding of intercultural proxemic behavior. "Americans must be willing to underwrite and participate in team research on a massive scale directed toward learning more about the interrelationship of man and his environment. "20 "In fine: proxemics has proved an enormously fruitful field of research despite the cloudiness of its guiding principle. The time may come, however, to tidy things up a bit even while advancing the empirical research. $" 21$ 
BIBLIOGRAPHY FOR CHAPTER I

${ }^{1}$ Hall, Edward T. 1963. "A System for the Notation of Proxemic Behavior." American Anthropologist 65: 1003. (hereafter cited "Notation").

$2_{\text {Tbid. p. } 1003 .}$

${ }^{3}$ Watson, O. Michael and Theodore D. Graves. 1966. "Quantitative Research in Proxemic Behavior." American Anthropologist 68: 971-85. (hereafter cited Watson and Graves.)

${ }^{4}$ Watson, O. Michael. 1972. "Conflicts and Directions in Proxemic Research." The Journal of Communication 22:446. (hereafter cited "C-onflicts").

${ }^{5}$ Cook, Mark. 1970. "Experiments on Orientation and Proxemics." Human Relations 63: 61-76.

${ }^{6}$ Forston, Robert F. and Charles U. Larson. 1968. "The Dynamics of Space: An Experimental Study in Proxemic Behavior among Latin Americans and North Americans." The Journal of Communication 18: 1.09-16.

${ }^{7}$ Goldberg, Gordon N. , Charles A. Kiesler, and Barry E. Collins. 1969. "Visual Behavior and Face to Face Distance During Interaction." Sociometry 32:43-53.

8 Hall, Edward T. 1966. The Hidden Dimension. New York: Doubleday. (hereafter cited "Dimension").

${ }^{9}$ Sommer, Robert. 1969. Personal Space. New Jersey: PrenticeHall.

10 Watson, O. Michael. 1970. Proxemic Behavior: A Cross-Cultural Study. The Hague: Mouton.

11 "Conflicts". p. 458.

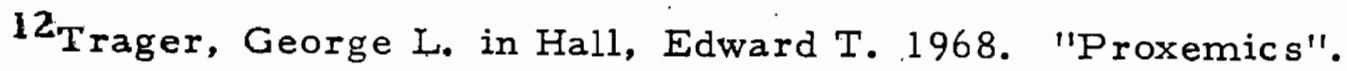
Current Anthropologist 9: 105.

${ }^{13}$ Wats on and Graves. p. 984 . 
${ }^{14}$ Ibid. p. 971.

${ }^{15}$ Tbid. p. 982 .

16 Tbid. p. 983.

17 'Notation"!. p. 1005.

18 Hall, Edwart T. 1964. "Adumbration in Intercultural Communication," in The Ethnography of Communication. ed. by American Anthropologist 66 (6), part 2, p. 160 .

19 Hall, Edward T. 1968. "Proxemics." Current Anthropologist 9: 95. (hereafter cited "Proxemics').

20"Dimension!". p. 186.

${ }^{21}$ McClellan, J.E. in "Proxemics" p. 103. 


\section{CHAPTER II}

\section{METHODS}

Eighteen Saudi-Arabian and eighteen American subjects interacted twice; once with a same-culture subject and once with a subject from the other culture. The resulting nine homogeneous SaudiArabian $\left(\mathrm{HO}_{\mathrm{SA}}\right)$ dyads, the nine homogeneous American $\left(\mathrm{HO}_{\mathrm{A}}\right)$ dyads, and the eighteen heterogeneous (HET) dyads were observed, televised and recorded on video tape through two-way mirrors from small observation rooms surrounding the larger room in which the interactions took place. Each interaction took seven minutes. Direct observation was made at the time of interaction and either two or three subsequent scorings were conducted upon viewing the video tapes. Data were analyzed with respect to proximity along the five dimensions of sociofugal-sociopetal axis, kinesthetic factors, touch code, visual code, and roice loudness. An additional analysis of degree of association among the five dimensions was made.

\section{SUBJECTS}

A Saudi-Arabian graduate student in anthroplogy was selected as a research assistant. He recruited eighteen male Saudi-Arabian stu- 
dent subjects who ranged in age from 21 to 31 years (mean average age was 24.05 years) and who had been in the United States from one and one-half to seven years (mean average length of stay was 4.31 years). All but two of the subjects were single. Eighteen male American students were recruited from a variety of undergraduate speech and graduate anthropology classes who ranged in age from 20 to 28 years (mean average age was 23.39 years).

\section{INSTRUCTIONS}

Each subject was told that he would be involved in two dialogues of approximately ten minutes duration, one with a same-culture subject and one with a pers on from another culture. Each subject was told that the dialogues would be recorded and that at some time during the dialogue they would be filmed. Each subject was given instructions as to time and location of the meeting. The subjects generally arrived in groups of two or four. Two of the subjects were escorted to the observation room. Outside of the door they were introduced, thanked for their participation, given a folding chair each, instructed to enter the room, sit anyplace they pleased, and talk about any topic for about ten minutes. The $\mathrm{HO}_{\mathrm{SA}}$ dyads were told that they may speak in Arabic if they desired. They were told that their conversation would be recorded and at some time during their dialogue they would be filmed. 


\section{OBSERVATIONS}

The observation room (ten and one-half feet by twenty-two feet) was marked off into one-foot squares by masking tape put on the floor. This permitted relatively accurate estimations of distance between subjects to be made. Three smaller practice rooms were situated on each of the two longer sides of the observation room. Each practice room had a two-way mirror that it shared with the observation room. A video tape camera, monitor and recorder was stationed in one of the practice fooms and this equipment was portable to allow moving to another practice room for a better angle if necessary. A microphone was located in the observation room and was connected to the video tape recorder. The controls were adjusted daily to achieve a baseline

for control. The camera recorded the subjects as they entered the room and set up their chairs. Then a two-minute warm-up period was allowed after which the next five minutes of interaction was filmed and recorded. The two-minute warm-up period served not only as an icebreaking period for the subjects but also as a time to move the video equipment if the subjects setup in a position difficult to film from the original position. In the case of particularly bad angles, after two and one-half minutes of the five-minute recording session the camera was moved to another location for the next two and one-half minutes. At the end of the five-minute period the subjects were thanked again for their cooperation and one of the pair was asked to remain while the other was taken to another room and asked to wait for a few minutes. Another subject was introduced to the remaining subject from the previous dialogue. 
At the end of that session, the subject who had now interacted twice was thanked for his participation, asked not to discuss his experience, and was dismissed. The other subject was then introduced to the subject who had been waiting in the other room. This routine was repeated until eighteen $\mathrm{HET}$, nine $\mathrm{HO}_{\mathrm{A}}$, and nine $\mathrm{HO}_{\mathrm{SA}}$ dyadic interactions had occurred and had been taped and recorded.

Five of Hall's eiǵht categories of proxemic behavior were employed for the observations: (a) sociofugal-sociopetal axis, (b) kinesthetic factors, (c) touch code, (d) visual code, and (e) voice loudness scale. The sociofugal-sociopetal axis scores the relation of the axis of one's shoulders to that of the other as illustrated below:

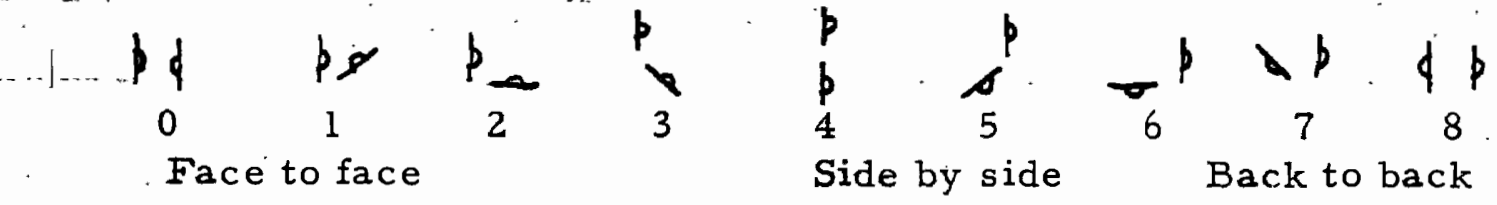

The Arabs were expected to be more direct, i. e., to score lower, than Americans. The kinesthetic factors category relates to the closeness of one person to another, and to the potential of each for holding, grasping, or touching the other and was scored on the following bases:

1. 0 within body contact distance

1. 5 just outside this distance

2. 0 within touching distance with forearm extended

2. 5 just outside this distance

3. 0 within touching distance with arm extended

3. 5 just outside this distance

4. 0 within touching distance by reaching

4. 5 just outside this distance

Arabs were expected to interact more closely than Americans. The 
touch code category provides for the amount of contact during each interaction, scored as follows:

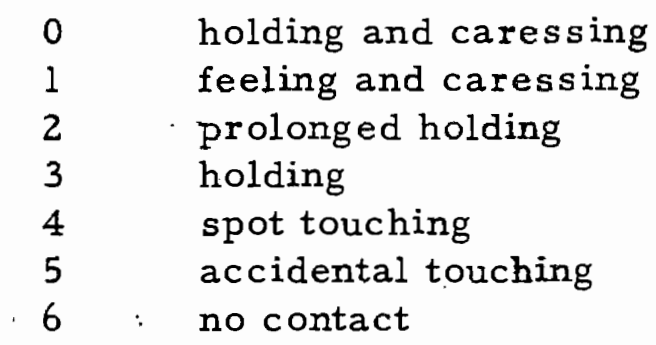

Arabs were"expected tó touch more than Americans. The visual code category was scored:

1 sharp (focusing directly on the other person's eyes)

2 clear (focusing about the other person's head and face)

3 peripheral (having the other person within the field of vision, but not focusing on his head or face)

4 no visual contact (looking down or gazing into space)

Arabs were expected to display greater, and more direct visual contact. The voice loudness scale was measured as follows:

$\begin{array}{ll}0 & \text { very loud } \\ 1 & \text { loud } \\ 2 & \text { normal plus } \\ 3 & \text { normal } \\ 4 & \text { soft } \\ 5 & \text { very soft } \\ 6 & \text { silent }\end{array}$

A rabs were expected to talk louder than Americans.

\section{SCORING}

Viewing of the video tapes was conducted following the direct observations. Notes taken during the on-the-spot viewing were consulted while viewing the video tapes. Each dyad was scored along the 
five dimensions, stopping or reversing the tape as necessary to obtain accurate scores. Following the initial video tape scoring, an uninformed accomplice was employed to repeat the procedure to both support the initial findings and to help prevent any built-in bias, Both scorers observed the tapes simultaneously and discussed each score for each dimension. The results were compared to those of the initial viewing and any-discrepancy was noted. Both scorers then analyzed the film again to resolve any discrepancies.

The resulting scores were then tabulated. Five t-tests for correlated means were computed for the $\mathrm{HO}_{\mathrm{SA}} / \mathrm{HO}_{\mathrm{A}}$ comparison. Twenty t-tests for independent means were calculated for $\mathrm{HET} / \mathrm{HO}_{\mathrm{SA}}$ comparison and $\mathrm{HET} / \mathrm{HO}_{\mathrm{A}}$ comparison. A random sample of the eighteen HET dyads was taken resulting in HET Sample A and HET Sample B of nine dyads each. Tests of significance were run for all twenty-five t-tests.

Ten Peasrson product moment correlations were calculated to test for possible positive correlation among the five dimensions for the $\mathrm{HO}_{\mathrm{SA}} / \mathrm{HO}_{\mathrm{A}}$ dyads. Ten Pearson product moment correlations were also conducted for the same purpose both for the $\mathrm{HO}_{\mathrm{A}}$ and $\mathrm{HO}_{\mathrm{SA}}$ dyads. Significance tests were conducted for all thirty Pearson product moment correlations. 


\section{CHAPTER III}

\section{RESULTS}

The hypothesis of this study is that Arabs will exhibit more directness in proxemic behavior than Americans. To test this hypothesis, eighteen Saudi-Arabian and eighteen American male students were observed as nine $\mathrm{HO}_{A}$, and eighteen HET dyads. Data were obtained, scored, and analyzed from video taped observations. Individual scores were averaged to arrive at dyadic scores. Twentyfive t-tests and thirty Pearson product moment correlations were computed to test for significance of differences or for significant positive correlations. No significant differences derived from the $t-$ : tests and three significant positive correlations emerged from the Pearson correlations.

Table I presents mean scores for all of the five proxemic variables that could be scored for Arabs as a group and for Americans as a group. Contrary to the hypothesis, no differences were noted.

To test for any possible statistical difference, five one-tailed t-tests for correlated means were calculated; one for each of the five dimensions. Tables II through VI present these results. 
TABLE. I

AMERICAN AND ARAB GROUP MEANS AND STANDARD

DEVIATIONS ON FIVE MEASURES OF

PROXEMIC BEHAVIOR

VARIABLE $\frac{1}{\text { MEAN SD }} \frac{2}{M E A N ~ S D} \cdot \frac{3}{M E A N ~ S D ~} \frac{4}{M E A N ~ S D} \frac{5}{M E A N ~ S D}$

SAUDI-

$\begin{array}{rlllllllllll}\text { ARABIAN } & 1.11 & .66 & 4 & . & .40 & 5.77 & .78 & 2.17 & .30 & 2.61 .47 \\ \text { AMERICAN } & 1.00 & .66 & 4 & & .40 & 5.55 & .78 & 2.11 & .30 & 2.44 .47\end{array}$

TABLE II

ARAB - AMERICAN DIFFERENCES

IN PROXEMIC BEHAVIOR

VARIABLE 1 - - AXIS

\begin{tabular}{llllll} 
& MEAN & SD & DF & $t$ & SIG \\
$\begin{array}{lllll}\text { ARABS } \\
\text { VS }\end{array}$ & 1.11 & .66 & & & \\
AMERICANS & 1.00 & .66 & & & \\
\cline { 2 - 6 }
\end{tabular}

No statistical significance was found for the sociofugal-sociopetal dimension between $\mathrm{HO}_{\mathrm{SA}}$ and $\mathrm{HO}_{\mathrm{A}}$ dyads.

TABLE III

ARAB - AMERICAN DIFFERENCES IN PROXEMIC BEHAVIOR

VARIABLE 2 -- KINESTHETICS

ARABS

vs.

AMERICANS

\begin{tabular}{lllll} 
MEAN & SD & DF & t & SIG \\
\hline 4 & 40 & & & \\
\hline & & 16 & 0 & NS \\
\hline 4 & .40 & & & \\
\hline
\end{tabular}


No statistical significance was found for the kinesthetics dimension between $\mathrm{HO}_{\mathrm{SA}}$ and $\mathrm{HO}_{\mathrm{A}}$ dyads.

\section{TABLE IV}

ARAB - AMERICAN DIFFERENCES IN PROXEMIC BEHAVIOR VARIABLE 3 -.. TOUCHING

\section{ARABS}

vs

AMERICANS

\begin{tabular}{lcccc} 
MEAN & SD & DF & $t$ & SIG \\
\hline 5.77 & .78 & & & \\
\hline 5.55 & & 16 & .57 & NS \\
\hline
\end{tabular}

No statistical significance was found for the touching dimension between $\mathrm{HO}_{\mathrm{SA}}$ and $\mathrm{HO}_{\mathrm{A}}$ dyads.

\section{TABLE V}

ARAB - AMERICAN DIFFERENCES IN PROXEMIC BEHAVIOR VARIABLE 4 --- VISUAL DIRECTNESS

ARABS

vs

AMERICANS

\begin{tabular}{lllll} 
MEAN & SD & DF & $t$ & SIG \\
\hline 2.17 & .30 & & & \\
\hline & & 16 & .43 & NS \\
\hline 2.11 & .30 & & & \\
\hline
\end{tabular}

No statistical significance was found for the visual directness dimension between $\mathrm{HO}_{S A}$ and $\mathrm{HO}_{\mathrm{A}}$ dyads. 
TABLE VI

ARAB - AMERICAN DIFFERENCES IN PROXEMIC BEHAVIOR VARIABLE 5 -.. VOICE LOUDNESS

\begin{tabular}{llllll} 
& MEAN & SD & DF & $t$ & SIG \\
ARABS & 2.61 & .47 & & & \\
vS & & & 16 & .85 & NS \\
AMERICANS & 2.44 & .47 & & & \\
\cline { 2 - 4 }
\end{tabular}

No statistical significance was found for the voice loudness dimension between $\mathrm{HO}_{\mathrm{SA}}$ and $\mathrm{HO}_{\mathrm{A}}$ dyads. Therefore, no statistically significant differences were shown to exist for any of the variables examined.

While no differences existed between the two cultural groups, differences could possibly exist between either or both of the cultural groups and the HET dyads. To test for any possible statistically significant difference of this nature twenty one-tailed $t$-tests for independent means were calculated. The eighteen HET dyads were, by random sample, divided into two sets of nine HET dyads, each of which were compared to the $\mathrm{HO}_{\mathrm{SA}}$ and $\mathrm{HO}_{\mathrm{A}}$ dyads. The results are presented in Tables VII through XI. 
TABLE VII

ARAB - AMERICAN DIFFERENCES IN PROXEMIC BEHAVIOR VARIABLE I -.. AXIS

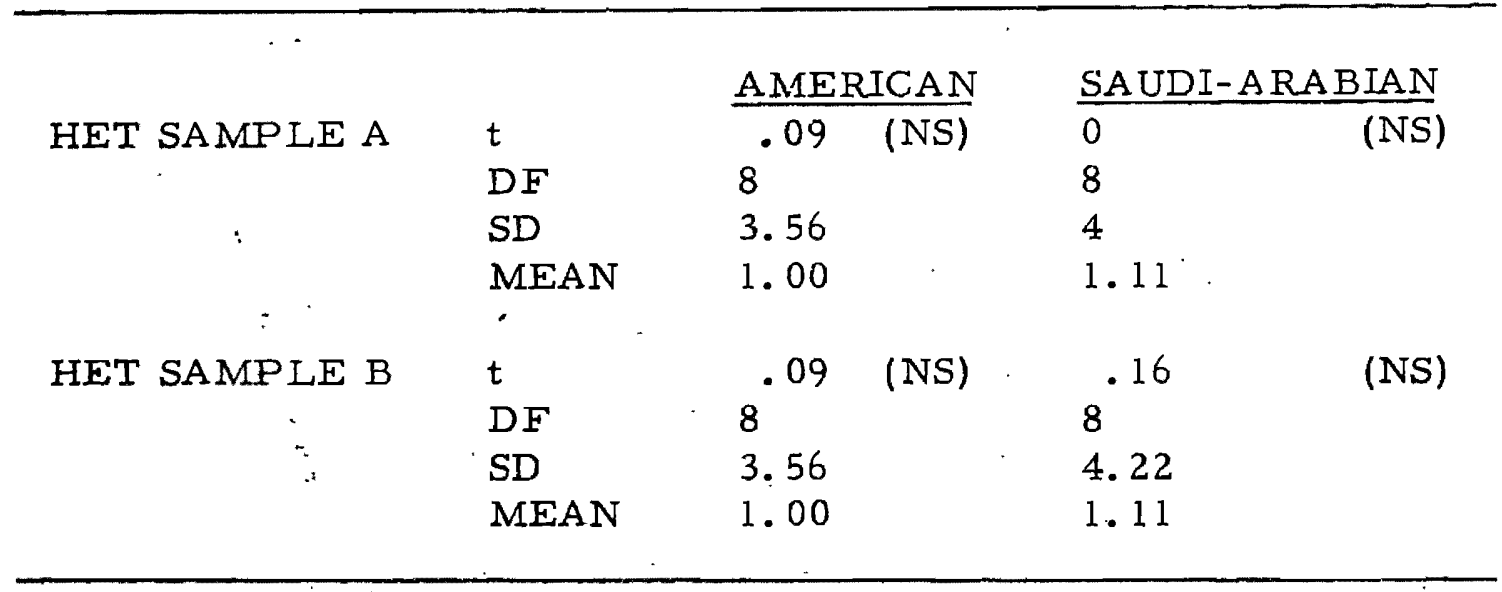

No statistically significant differences were found'to exist between the HET samples and the American and Saudi-Arabian dyads for the sociofugal-sociopetal dimension.

\section{TABLE VIII}

ARAB - AMERICAN DIFFERENCES IN PROXEMIC BEHAVIOR VARIABLE 2 - - KINESTHETICS

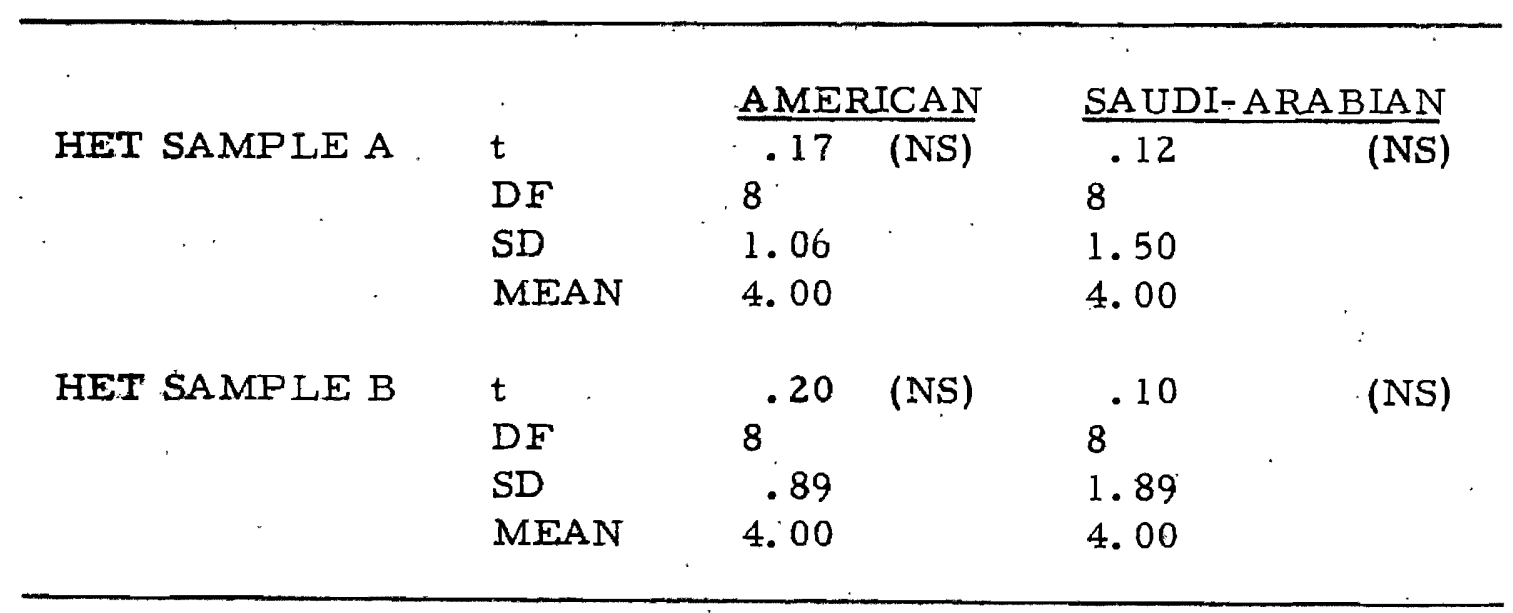


No statistically significant differences were found to exist between the HET samples and the American and Saudi-Arabian dyads for the kinesthetic dimension.

TABLE IX

ARAB - AMERICAN DIFFERENCES IN PROXEMIC BEHAVIOR VARIABLE $3 \ldots$ TOUCHING

\begin{tabular}{|c|c|c|c|c|c|}
\hline \multirow[b]{2}{*}{ HET SAMPLE A } & \multirow[b]{2}{*}{$\begin{array}{l}t \\
\text { DF } \\
\text { SD } \\
\text { MEAN }\end{array}$} & \multicolumn{2}{|c|}{ AMERICAN } & \multicolumn{2}{|c|}{ SAUDI-ARABIAN } \\
\hline & & $\begin{array}{l}0 \\
8 \\
0 \\
5.56\end{array}$ & (NS) & $\begin{array}{l}8^{.08} \\
8 \\
5.77\end{array}$ & (NS) \\
\hline HET SAMPLE B & $\begin{array}{l}t \\
\text { DF } \\
\text { SD } \\
\text { MEAN }\end{array}$ & $\begin{array}{l}.21 \\
6.22 \\
5.56\end{array}$ & (NS) & $\begin{array}{l}8.18 \\
3.56 \\
.5 .78\end{array}$ & (NS) \\
\hline
\end{tabular}

No statistically significant differences were found to exist between the HET samples and the American and Saudi-A rabian dyads for the touching dimension.

TABLE $X$

ARAB - AMERICAN DIFFERENCES IN PROXEMIC BEHAVIOR VARIABLE 4 -.. VISUAL DIRECTNESS

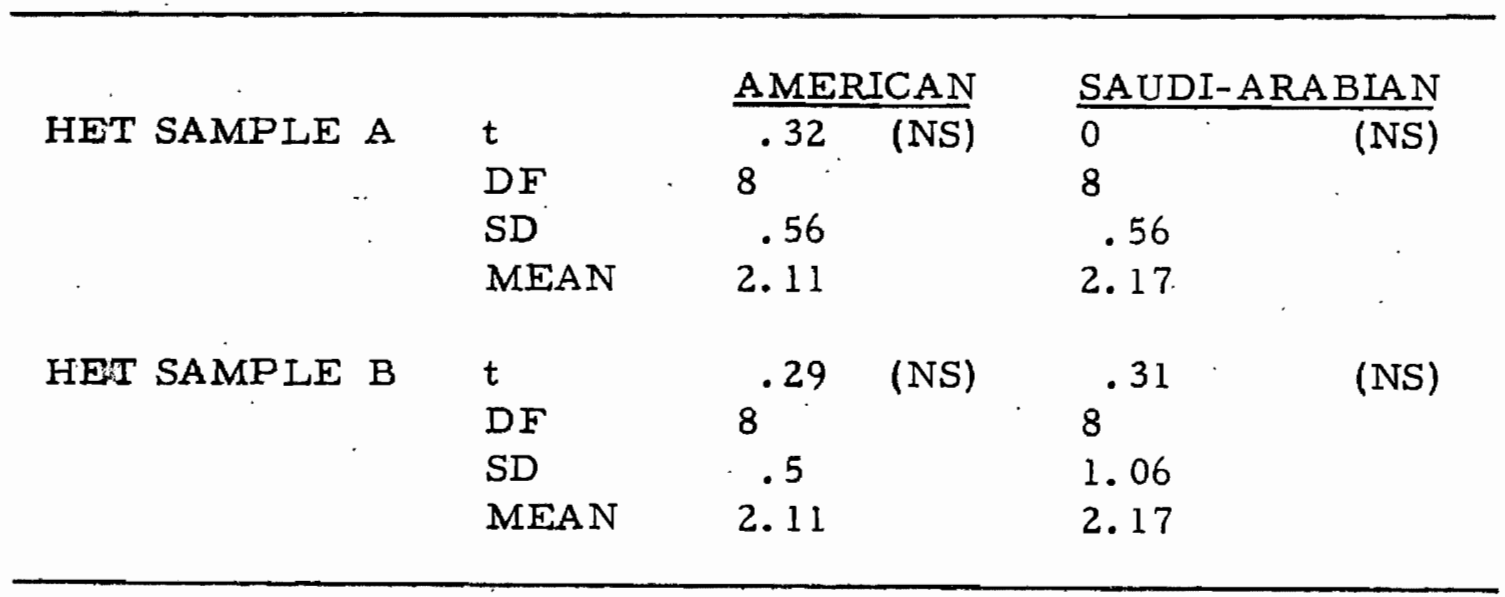


No statistically significant differences were found to exist between the HET samples and the American and Saudi-Arabian dyads for the visual directness dimension.

\section{TABLE XI}

ARAB - AMERICAN DIFFERENCES IN PROXEMIC BEHAVIOR VARIABLE 5 -.- VOICE LOUDNESS

\begin{tabular}{|c|c|c|c|c|c|c|c|}
\hline \multirow[b]{2}{*}{ HET } & \multirow[b]{2}{*}{ SAMPLE } & \multirow[b]{2}{*}{$\mathrm{A}$} & \multirow{2}{*}{ t } & \multicolumn{2}{|c|}{ AMERICAN } & \multicolumn{2}{|c|}{ SAUDI-ARABIAN } \\
\hline & & & & $\overline{1}$ & $(\mathrm{NS})$ & $\overline{0}$ & $\overline{(N S)}$ \\
\hline & $=$ & & $D F$ & 8 & & 8 & \\
\hline & $\therefore$ & & $S D$ & & & 1.5 & \\
\hline & & & MEAN & & & 2.61 & \\
\hline \multirow[t]{4}{*}{ HET } & SAMPLE & $B$ & $t$. & 0 & (NS) & .52 & (NS) \\
\hline & & & DF & 8 & & 8 & \\
\hline & & & $\mathrm{SD}$ & 1 & 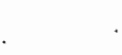 & 1 & \\
\hline & & & MEAN & & & 2.61 & \\
\hline
\end{tabular}

No statistically significant differences were found to exist between the HET samples and the American and Saudi-Arabian dyads for the voice loudness dimension. Therefore, no differences were found to exist for any of the twenty $\dot{t}$-tests calculated contrary to the hypothesis.

While no significant differences were found to exist for any of the t-tests calculated, possible positive correlation could exist among the five dimensions. To test for this possibility, ten Pearson product moment correlations were calculated for the $\mathrm{HO}_{\mathrm{SA}}$ and $\mathrm{HO}_{\mathrm{A}}$ dyads. Table XII displays the results. 
TABLE XII

PEARSON CORRELATIONS AMONG FIVE MEASURES OF PROXEMIC BEHAVIOR $N=18$ ( 9 American and 9 Saudi-Arabian dyads)

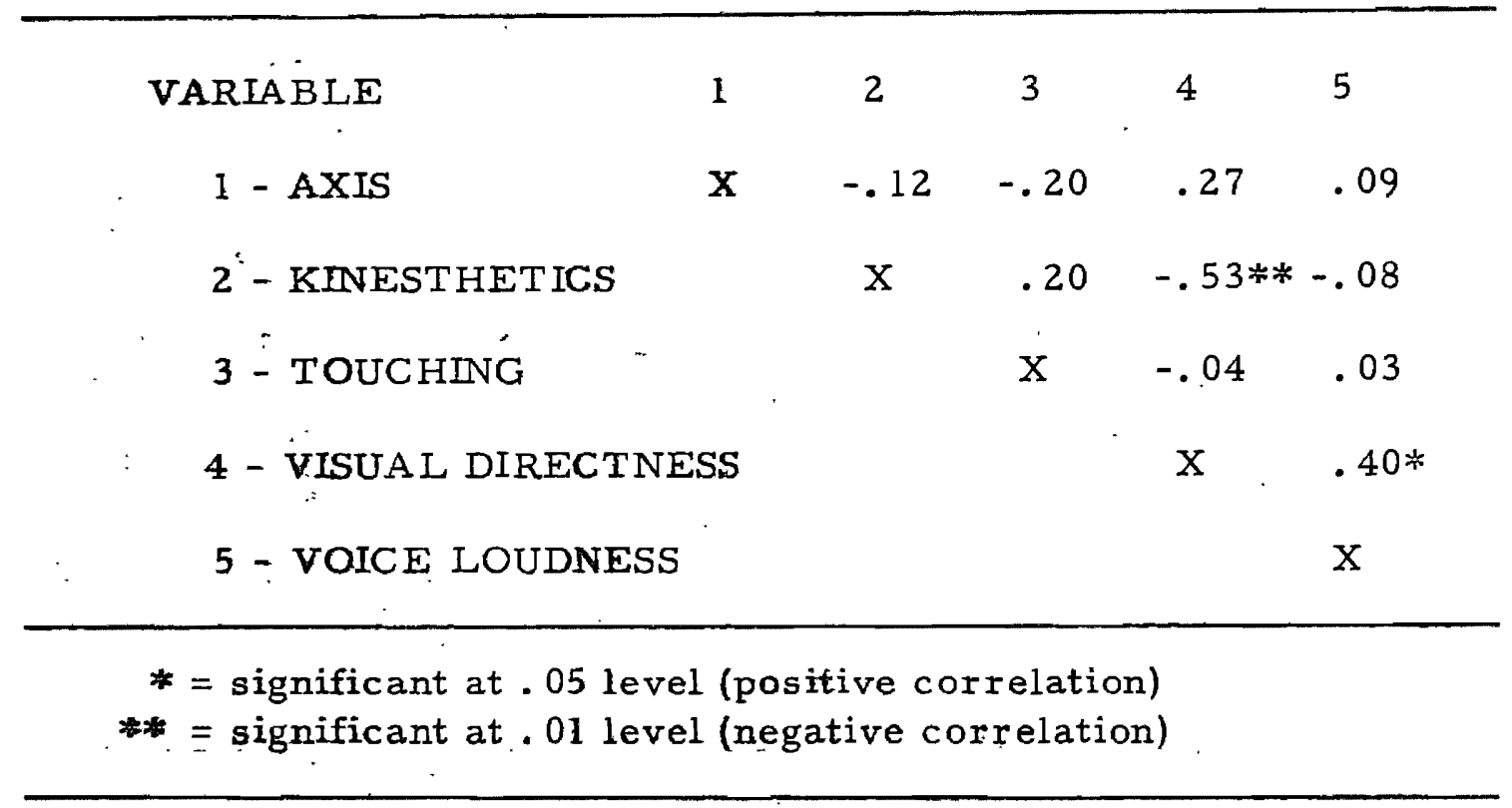

Because of the very low level of correlation found (only the visual directness - voice loudness dimension produced a significant positive correlation) ten Pearson product moment correlations were calculated to test for possible positive correlation among the dimensions in each cultural group separately. Tables XIII and XIV illustrate the results. 
TABLE XIII

PEARSON CORRELATIONS AMONG FIVE MEASURES OF PROXEMIC BEHAVIOR FOR

9 AMERICAN DYADS

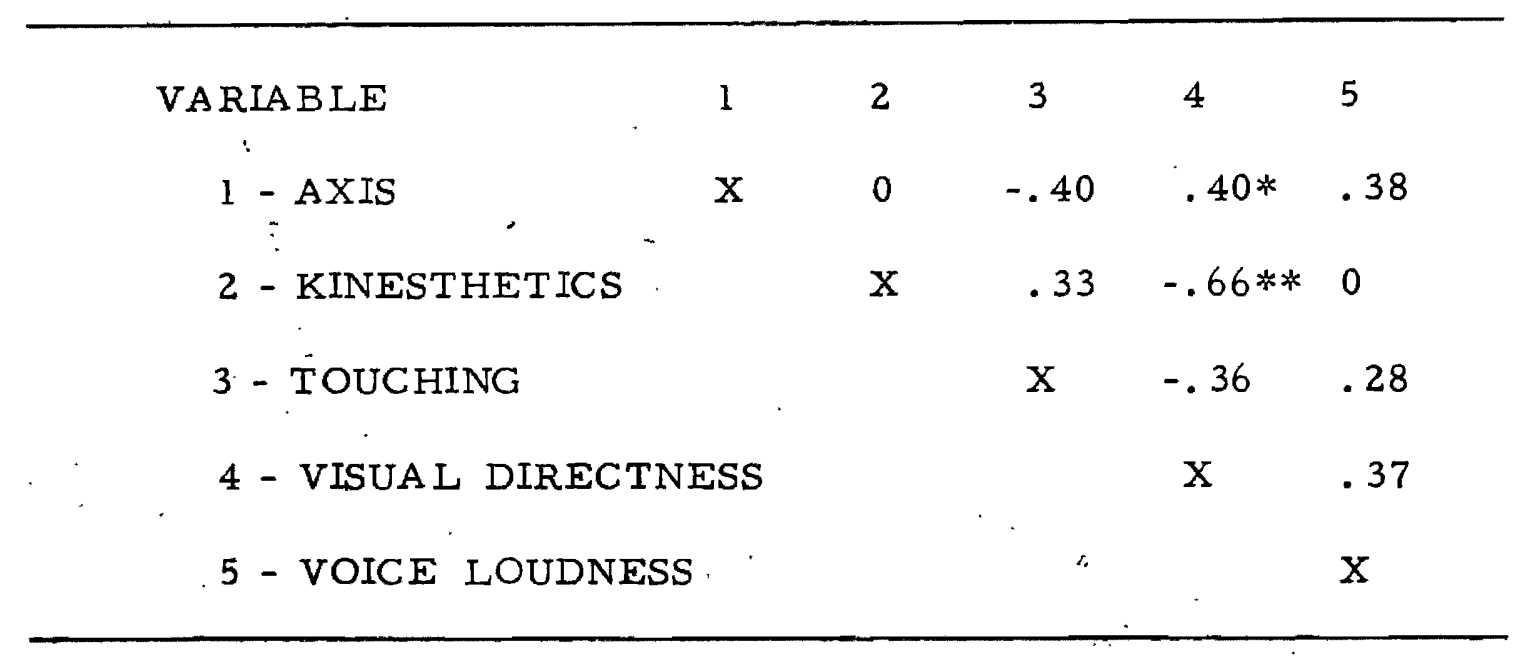

* = significant at . 05 level (positive correlation)

** = significant at. 01 level (negative correlation)

Only the sociofugal-sociopetal - visual directness category produced a significant positive correlation although the visual directness voice loudness category approached significance. 
TABLE XIV

PEARSON CORREIATIONS AMONG FIVE MEASURES OF PROXEMIC BEHAVIOR FOR

9 AMERICAN DYADS

\begin{tabular}{|c|c|c|c|c|c|}
\hline VARIABLE & 1 & 2 & 3. & 4 & 5 \\
\hline $1:-A X I S$ & $\mathrm{x}$ & -.29 & .07 & .20 & -.26 \\
\hline $2 \vdots$ KINESTHÉTICS & & $\mathrm{X}$ & 0 & $-.50 * *$ & $.18^{\circ}$ \\
\hline 3 - TOUCHING & & & $\mathrm{X}$ & .18 & -.30 \\
\hline \multicolumn{2}{|c|}{4 - VISUAL DIRECTNESS } & & & $\mathrm{X}$ & $.42 *$ \\
\hline 5 - VOICE LOUDNES & & & " & & $\mathrm{X}$ \\
\hline
\end{tabular}

* = significant at . 05 level (positive correlation)

**-=-significant at . 01 level (negative correlation)

Only the visual directness - voice loudness category produced a significant positive correlation. Therefore, only three categories of the three tested showed significant positive correlation. Moreover, the kinesthetics - visual directness category for all three sets of Pearson correlations showed a significant negative correlation.

Twenty-five t-tests were calculated to test the possibility of significant difference in proxemic behavior between Americans and Saudi-Arabians along five dimensions. No differences were noted. Thirty Pearson correlations were calculated to determine any possible significant positive correlations among the five variables. 
Not only were three significant positive correlations found, three significant negative correlations were discovered. 
The most important outcome of this study is that the results are in direct contradiction of the research project being replicated. Five t-tests were calculated to test for the possibility of significant difference in proxemic, behavior between $\mathrm{HO}_{\mathrm{SA}}$ and $\mathrm{HO}_{\mathrm{A}}$ dyads along the five dimensions of sociofugal-sociopetal axis, kinesthetic factors, touch code, visual code, and voice loudness scale. No significant differences were found. Twenty t-tests were calculated to test for the possibility of significant differences in proxemic behavior between two HET dyadic groups and $\mathrm{HO}_{\mathrm{SA}}$ and $\mathrm{HO}_{\mathrm{A}}$ dyads along the five dimensions. No significant differences were found. Inasmuch as no significant differences were found for any of the t-tests, the hypothesis that Arabs (as represented in the sample) will exhibit.significant differences in proxemic behavior from Americans, with Arabs being closer and more direct in their proxemic behavior than Americans was not supported. Watson and Graves found significant differences between Arabs and Americans along all five of the dimensions. This study examined HET dyads as an extra measure of analyzing intercultural proxemic behavior but differences failed to appear.

Ten Pearson correlations each were calculated to determine any possible significant positive correlation among the five dimensions for 
the $\mathrm{HO}_{\mathrm{SA}}-\mathrm{HO}_{\mathrm{A}}$ dyads, for the $\mathrm{HO}_{\mathrm{A}}$ dyads, and for the $\mathrm{HO}_{\mathrm{SA}}$ dyads. Significant positive correlation was found in the $\mathrm{HO}_{\mathrm{SA}}-\mathrm{HO}_{\mathrm{A}}$ dyads between visual directness and voice loudness. Wats on and Graves found high positive correlation among all the dimensions. Watson and Graves did not find these correlations to exist in the $\mathrm{HO}_{\mathrm{SA}}$ and $\mathrm{HO}_{\mathrm{A}}$ dyads separately. This study found significant positive correlation to exist between axis and visual directness dimensions in the $\mathrm{HO}_{\mathrm{A}}$ dyads and between the visual directness and voice loudness dimensions in the $\mathrm{HO}_{\mathrm{SA}}$ dyads. Watson and Graves reported no positive correlations among variables in these groups. This study found significant negative correlation to exist between the kinesthetics and visual directness dimensions. No such correlation was found in the Watson and Graves' study.

Three interesting patterns did emerge from the Pearson correlations, however. The visual directness - voice loudness matrix showed significant positive correlation for both the American - SaudiArabian and Saudi-A rabian dyads and approached significance in the American dyads. The sociofugal-sociopetal - visual directness category produced a significant positive correlation in the American dyads and approached significance in the other two groupings. Perhaps the most interesting feature of the Pearson correlations, though, is the significant negative correlation of the kinesthetic - visual directness variable. This supports Argyle and Dean's study which 
found that, "as predicted, there was less eye-contact and glances were shorter, the closer two subjects were placed together...."1

One can speculate on the possible reasons for the results of this research project reversing the findings of Watson and Graves' study: A partial explanation might be found in the utilization of larger samples and repetitive measures but more rigorous research techniques are probably not the only reasons for the reversal. This study was conducted six years after the pilot project and many changes have occurred in the world, including Saudi-Arabia and the United States. The Arabian students in this study had been in this country for more than four and a quarter years on the average and, while not reported by Wats on and Graves, that length of time may have been greater than that for those students in the earlier study. The "Americanization of Mohammed" is a factor to be considered.

Other possible explanations exist for the apparent similarities that seem to exist between Arab and American proxemic behavior although they do not explain why Watson and Graves found such significant differences to exist between his Arab and American subjects. One could hypothesize that Saudi-Arabians are highly adaptable to new cultures and environments and that the similarities are based partially on this adaptability. One could also argue that the SaudiArabian students in the sample in the present study are generally urban, highly educated, well-traveled, and members of the higher 
socio-economic stratum and therefore not representative of the population of their country just as Watson described his Arab subjects. All of the subjects in the present study were mostly, too, students of anthropology and of speech communication; two disciplines actively engaged in non-verbal communication behavior investigation.

A decade ago, the interested scholar could find little, in book form, about non-verbal communication. .. In sharp contrast, the 1970's have seen an explosion of new literature dealing with non-verbal communication.... In addition, a whole body of popular literature has grown up out of encounter groups, sensitivity training, body awareness, massage, etc. ${ }^{2}$

Perhaps an increased sensitivity to proxemics was a factor that influenced both Arabs and Americans in their interactions both in the homogeneous and heterogeneous encounters. Awareness of non-verbal communication behavior studies or literature, however, does not address the basic tenet that this behavior often exists at the subconscious level and that cultural patterns also exist largely out-ofawareness.

\section{SUGGESTIONS}

Further research in the area still needs to be conducted. Still larger samples are needed to enable one to generalize from the results to whole populations.

Hall's system for the notation of proxemic behavior was, for the most part, found to be workable. The visual directness dimension 
requires multi-angular observation to be accurately scored. The voice loudness scale, by definition, is subjective. Objective measures need to be developed. Very well-controlled audio equipment must be used because of so many variable factors influencing this dimension from day to day. This study had to rely too much on impression to give much confidence in the voice-loudness variable.

While (as Watson later. reported) a laboratory setting is required:

..... in order to study proxemic behavior under conditions which were as constant as possible for all subjects, a laboratory setting was the only practicable situation which allowed the degree of control ... necessary to isolate proxemic behavior from factors which may have had an influence on it, $^{3}$

one could hope for a less laboratory-like laboratory: less clinical and sterile; in which to conduct the observations and interactions. Because this study utilized video tape for observation, repetitive measures were and are possible. In addition, one could do further study in such areas as content and linguistic analysis and kinesics. Hopefully, further study in this area will be conducted which will advance the understanding of proxemic behavior. 


\section{A SELECTED BIBLIOGRAPHY}

Argyle, Michael and Dean, Janet. "Eye Contact, Distance and Affiliation." Sociometry, 28(1965): 289-304.

Cook, Mark. "Experiments on Orientation and Proxemics." Human Relations, 63(1970): 61-76.

Forston, Robert F. and Larson, Charles U. "The Dynamics of Space: An Experimental Study in Proxemic Behavior among Latin Americans and North Americans." The Journal of Communication, 18(1968): 109-16.

Goldberg, Gordon N., Kiesler, Charles A. and Collins, Barry E. "Visual Behavior and Face to Face Distance During Interaction." Sociometry, 32(1969): 42-53.

Hall, Edward T. "A System for the Notation of Proxemic Behavior." American Anthropologist, 65(1963): 1003-26.

Hall, Edward T. "Adumbration in Intercultural Communication." In The Ethnography of Communication, edited by American Anthropologist, 66 (6), part 2 (1964): 154-63.

Hall, Edward T. "Proxemics." Current Anthropologist, 9(1968): 83-108.

Hall, Edward T. The Hidden Dimension. New York: Doubleday, 1966.

Harrison, Randall P., Cohen, Akiba A., Crouch, Wayne W., Genova, B.K. L. and Steinberg, Mark. "The Nonverbal Communication Literature." The Journal of Communication, 22(1972): 460-76.

Sommer, Robert. Personal Space. Englewood Cliffs, New Jersey: Prentice-Hall, 1969.

Watson, O. Michael. "Conflicts and Directions in Proxemic Research." The Journal of Communication, 22(1972): 443-59.

Watson, O. Michael. Proxemic Behavior: A Cross-Cultural Study. The Hague: Mouton, 1970.

Watson, O. Michael and Graves, Theodore D. "Quantitative Research in Proxemic Behavior." American Anthropologist, 68(1966): $971-85$. 
${ }^{1}$ Argyle, Michael and Janet Dean. 1965. "Eye Contact, Distance and Affiliation." Sociometry 28: 289.

${ }^{2}$ Harrison, Randall P., Akiba A. Cohen, Wayne W. Crouch, B.K. L. Genova and Mark Steinberg. 1972. "The Nonverbal Communication Literature." The Journal of Communication 22: 460.

"Conflicts". p. 447. 